\title{
Ground improvement using an expandable polyurethane resin
}

\author{
Mohanad Sabri ${ }^{1, *}$, Aleksandr Bugrov ${ }^{1}$, Stanislav Panov ${ }^{2}$, Viacheslav Davidenko ${ }^{2}$ \\ ${ }^{1}$ Peter the Great St. Petersburg Polytechnic University, St. Petersburg, Russia \\ ${ }^{2}$ The All-Russian research institute of hydraulic engineering of the name B.E.Vedeneyeva, St. Petersburg, Russia
}

\begin{abstract}
The paper describes an experiment conducted to study the effect of injection an expandable polyurethane resin on the stabilization, settlement reduction and increasing the bearing capacity of the foundation's soil. The experiment was carried out in sandy soil, and different types of soil investigations were carried out to investigate the effect of the resin on the soil properties beneath a concrete foundation. Results of Plate load test PLT and dynamic cone penetration test DCPT before and after the injection of the expandable resin are demonstrated and discussed in this paper.
\end{abstract}

\section{Introduction}

Different traditional methods are used for several applications of soil improvement in order to compensate settlements and to increase the bearing capacity of the soil beneath the existing constructions. These methods are classified mainly according to the type of techniques used or according to the material used for the stabilization process. Cement, fly ash, lime, chemical stabilization, and other materials are used in the fields of soil stabilization effectively [1-8]. Jet grouting, mechanical stabilization, micro piles, geosynthetic, biotechnical and other techniques are widely used in the field of settlement compensation and soil reinforcement[9-13]. However, each technique and material have a field of application, advantages besides the disadvantages or limitations of use at different sites conditions and different soil types. Moreover, different factors affect the selection of the appropriate method used for each case such as the type of the soil, the size of the construction, the cost of the method and other factors[14-16]. Furthermore, in particular situations, the settlement of constructions occurs in a soil which contains organic materials or acids which might react with the materials of the method used for the ground improvement. The speed of the stabilization method plays an important especially in vital roads or aerodromes and other types of constructions where long treatment process at these sites might be not effective leading to close the job sites causing many problems [17-20]

An innovative alternative method is the soil injection technology using an expandable polyurethane resin which improves the properties of the soil rapidly beside lifting and remediation of the constructions built on it.

\section{Methods}

A full-scale experiment was conducted to study the effect ofan expandable Polyurethane resin on the leveling of a concrete foundation and to investigate the effect of the injected resin on the improvement of various sand characteristics. A sandy soil beneath a concrete foundation was injected and treated with an expandable polyurethane resin consists of two components at different depths up to two meters. The soil was investigated before and after the injection of the resin at different points using different types of testing such as the dynamic cone penetration test DCPT and the plate load test PLT. Besides, a reference plot was chosen beside the injected plot for the comparison of the results of the investigation.

The injected area is 9 -meter square $(3 \times 3 \mathrm{~m})$ was cut to apply the lifting technology. An excavation process was carried out to perform the plate load test PLT at different depths and to locate the propagation of the resin in the soil massive.

\footnotetext{
${ }^{*}$ Corresponding author: mohanad.m.sabri@gmail.com
} 


\section{Results and discussion}

The reaction of the resin occurred immediately leading to the lifting process and hardened in the soil massive, and around $80 \%$ of the resin strength is obtained within the first minute. The concrete foundation was lifted and regulated up to $1 \mathrm{~cm}$ as planned for this experiment. Overall, ten comparison points were selected for the results comparison of the dynamic cone penetration test DCPT. The results of the DCPT test have shown an enormous increase in the dynamic resistant of the soil beneath the lifted foundation as shown in figure 1.

The resin propagates forming stingers or reinforcement in the soil massive leading to the strengthening of the soil as shown in figure 2.

The results of the plate load test have shown the ability of the resin on foundations strengthening increasing of the bearing capacity up to twice more than the initial value before the injection of the resin. The soil deformation modulus at different tested points and different depth increased remarkably after the injection of the expandable resin as shown in the table 1.

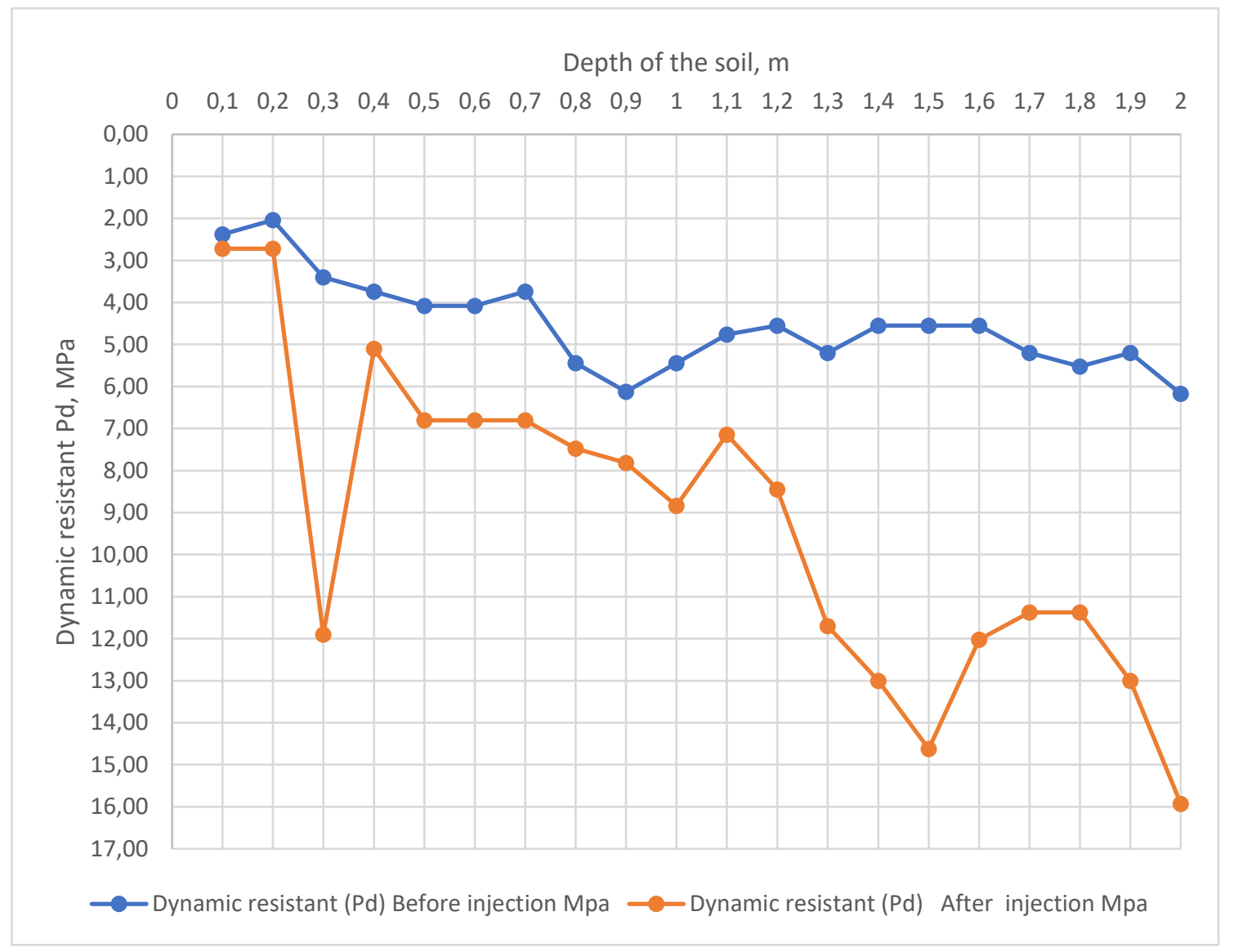

Fig. 1. The results of one comparison points of the dynamic cone penetration test before and after the injection of the expandable resin 


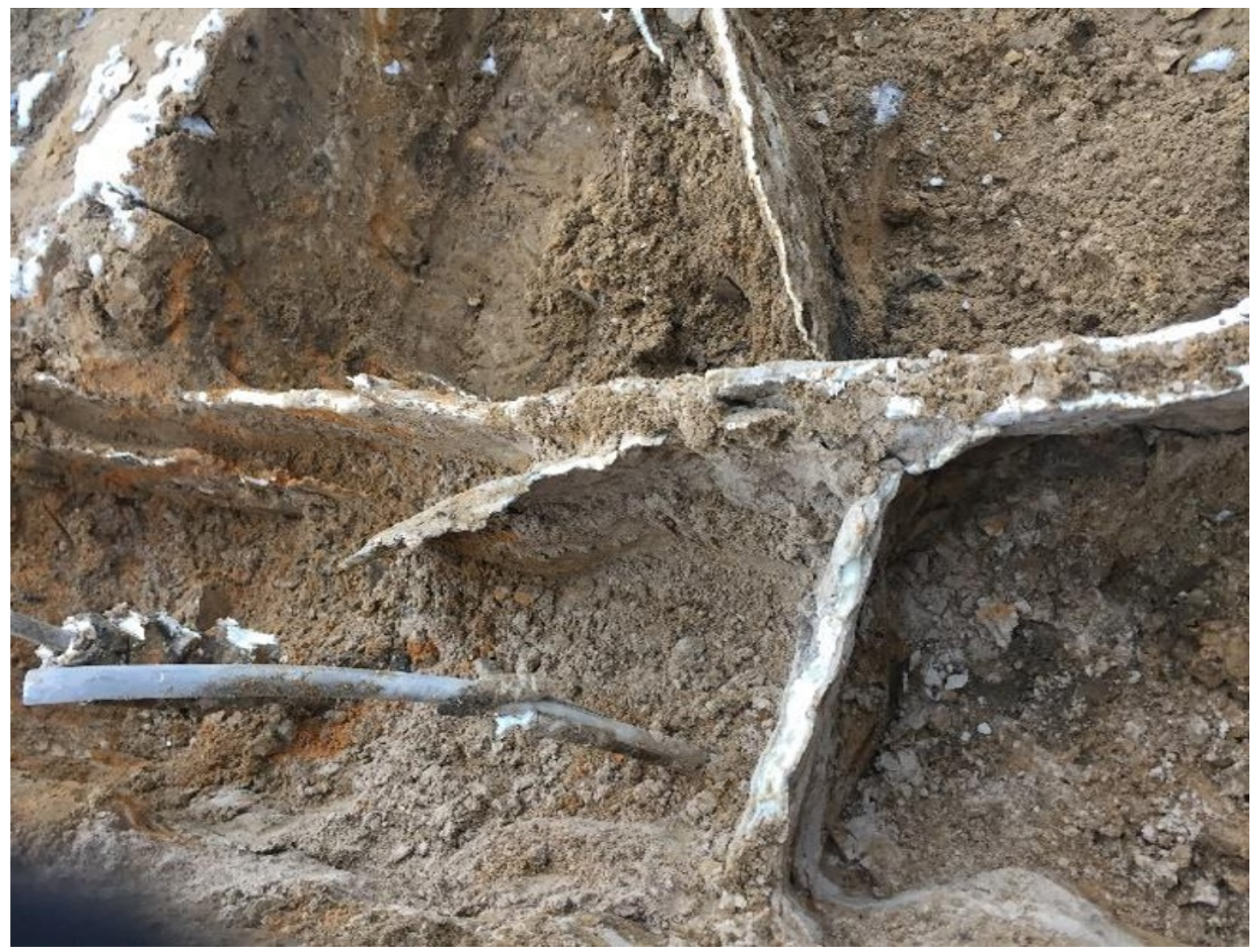

Fig. 2. The propagation of the resin in the soil massive as seen after the excavation process.

\begin{tabular}{|c|c|c|}
\hline Depth, $\mathrm{m}$ & $\begin{array}{c}\text { Deformation modulus in the } \\
\text { reference area }\end{array}$ & $\begin{array}{c}\text { Deformation modulus in the } \\
\text { injected area }\end{array}$ \\
\hline 0.4 & 10.6 & 16.4 \\
\hline 1.2 & 11.1 & 33.6 \\
\hline
\end{tabular}

Table 1. Results of the soil deformation modulus at different soil depth before and after the injection of the resin.

\section{Conclusion}

An experiment was conducted to study the effect of an expandable polyurethane resin on different soil properties besides lifting a concrete foundation. The results of different investigations have shown the significant improvement of the properties of the soil beneath the foundation after the injection of the expandable polyurethane resin. The deformation modulus of the resin was increased up to twice, the settlement decreased, and the bearing capacity of the soil increased immensely after the injection of the expandable resin improves the ability of the resin to compensate settlements and stabilize foundations beneath constructions and improving the soil properties without adverse effects on the soil ecology.

\section{References}

1. S. Kazemian, A. Prasad, B.B.K. Huat, V. Ghiasi, S. Ghareh. Arab. J. Sci. Eng. 37 (2012). 
2. C.H. Hurley, T.H. Thornburn. Highw. Res. Rec. 381 (1972).

3. S.-C. Chien, C.-Y. Ou, W.-W. Lo. Proc. Inst. Civ. Eng. - Geotech. Eng. 167 (2014).

4. H. Moayedi, M. Mosallanezhad, R. Nazir, S. Kazemian, B.K. Huat. Geotech. Geol. Eng. 32 (2014).

5. N.A. Larionova, E.N. Samarin, S.D. Voronkevich, T.T. Abramova. in Geotechnical Special Publication (2012)

6. P.L. Domone. Cem. Concr. Res. 20 (1990).

7. H. Moayedi, B.B. K Huat, S. Kazemian, S. Daneshmand. Int. J. Phys. Sci. 7 (2012).

8. C. Ma, Z. Qin, Y. Zhuang, L. Chen, B. Chen. Soils Found. 55, Pp 1222-1232 (2015).

9. D. Senapathy, H., Davie, J.R., Boehm. 120 I, Pp 440-451 (2003).

10. D.. Boehm, T. Posey, Geotechnical Special Publication. ASCE, 330-341 (2003).

11. J.N. Shirlaw. Grouting 2003. ASCE, Pp 257-268 (2003). doi:10.1061/40663(2003)104

12. Z.F. Wang, S.L. Shen, C.E. Ho, Y.H. Kim. Geotech. Eng. J. SEAGS AGSSEA 44 (2013).

13. G.K. Burke. in Geotechnical Special Publication. ASCE, 168, (2007).

14. K.A. Alsaffar. Int. J. Eng. Res. Dev. 10, Pp 67-70 (2014).

15. V. Grebneva, K. Utkina, M. Sabri, O. Stolyarov. in Innovative Technologies in Development of Construction Industry 725, Pp 611-616 (Trans Tech Publications, 2015).

16. P.G. Atangana Njock, J.S. Shen, G. Modoni, A. Arulrajah. Arab. J. Sci. Eng. 43 (2018).

17. A. Janalizadeh, A. Zahmatkesh. J. Rock Mech. Geotech. Eng. 7, Pp 532-539 (2015).

18. A. Hanna et al. J. Geotech. Geoenvironmental Eng. 143 (2017).

19. D. Costa, J.D. Rodrigues. 12th Int. Congr. Deterior. Conserv. Stone (2013).

20. C. Di Maio, R. Vassallo, M. Vallario. Eng. Geol. 162, Pp 53-66 (2013).

21.O.P. Minaev. Power Technol. Eng. 51 (5) (2018)

22. A.Y. Ivanov, Chernogorskiy, S.A., Vlasov, M.P. Mag. Civ. Eng.80 (4) (2018)

23. O.P. Minaev. Mag. Civ. Eng. 51 (7) (2014) 